Ocula ${ }^{15}$

Commemorating Charles S. Peirce (1839-1914):

interpretive semiotics and mass media

A cura di Giampaolo Proni e Salvatore Zingale

Novembre 2014 I www.ocula.it - DOI: 10.12977/ocula38

\title{
Peirce, rhetoric and the still image
}

Tony Jappy

University of Perpignan Via Domitia, France

anthony.jappy@wanadoo.fr

\begin{abstract}
After examining the evolution of Peirce's changing conceptions of rhetoric in the period 1903-06 the paper explores some of the implications of a 1904 paper on rhetoric and scientific writing and then examines the rhetorical potential of Peirce's definition of hexadic semiosis and the six-element classification system it generates with respect to a small corpus of photographic illustrations.
\end{abstract}

\section{Keywords}

Rhetoric, Hexadic semiosis, Hexadic classification, Classes of signs, Photographs

\section{Contents}

1. The demise of speculative rhetoric

1.1 Chronological considerations

1.2 The commens draft of March 1906

1.3 Hexadb

2. Peircean contributions to a modern rhetoric

2.1 The rhetorical potential of the hexad

2.2 Hexadb

Conclusion

References 


\section{Ocula $a^{15}$}

Commemorating Charles S. Peirce (1839-1914): interpretive semiotics and mass media

Tony Jappy, Peirce, rhetoric and the still image

I should still opine that in the future there probably will be three such sciences [speculative grammar, critic and speculative rhetoric/methodeutic]. But I have learned that the only natural lines of demarcation between nearly related sciences are the divisions between the social groups of devotees of those sciences; and for the present the cenoscopic studies (i.e., those studies which do not depend upon new special observations) of all signs remain one undivided science, - a conclusion I had come to before I made your acquaintance, but which the warm interest that you and I have in each other's researches in spite of the difference in their lines, decidedly confirms. (Draft dated 24 Dec., 1908, CP 8.342; EP2 482)

As early as 1867 , in his paper on the new list of categories, Peirce had broadened the traditional field of logic to a new 'trivium' of sciences comprising three components - formal grammar, logic and formal rhetoric - each concerned with a specific aspect of the discipline (CP 1.559). He was later to state that the cenoscopic, 'common' logical sciences of speculative grammar, logic and speculative rhetoric 'may be called the philosophical trivium' (EP2 19, 1895). Finally, in 1903 Peirce broadened the scope of this general logic by defining it as the 'Philosophy of Representation', by which term he meant 'representation [which] can be known without any gathering of special facts beyond our ordinary daily life' (CP 1.539): in other words, acquaintance with representations without recourse to the use of specialist instruments or the complex practices of the laboratory. The term thus covers not only the sort of technical representations Peirce was interested in as a logician but also the myriad representations with which we are ordinarily confronted in our everyday lives. The ambition of such an enterprise is staggering: logic was to be the general 'philosophy' of all representation - written, spoken, pictorial, olfactive, gustative and, indeed, tactile. Within this general philosophy of representation he posited the three related heuretic disciplines - speculative grammar, critic and speculative rhetoric or methodeutic - mentioned in the extract above.

Unfortunately, although he worked at the problem until 1909 at least, he never completed his grand philosophy of representation nor did he ever quite complete a satisfactory definition of speculative rhetoric, even abandoning the concept explicitly in 1906 in favour of methodeutic (CP 4.9). However, he did contribute important suggestions concerning the freeing of rhetoric from some of its traditional constraints, and one construct from his 1903 conception of sign and (implicitly) of semiosis, namely the hypoicons, provides an important module for the distinction between literal and figurative representation, so important in traditional discussions of rhetoric stretching back at least to Aristotle. Moreover, in the article 'Ideas, Stray or Stolen about Scientific Writing' published in 1904 he developed a less general, more specific 'idioscopic' conception of rhetoric organized according to three 'modes of specialization'. Finally, the hexadic systems of the period 1906 to 1908 also 


\section{Ocula $a^{15}$}

Commemorating Charles S. Peirce (1839-1914): interpretive semiotics and mass media

Tony Jappy, Peirce, rhetoric and the still image

provide an innovative background to rhetorical analysis, and it is these which will receive most attention here.

The paper is in two parts. After examining the influence of the emergence of the hexadic system of signs on the evolution of Peirce's changing conceptions of speculative rhetoric in the first, the paper explores some of its implications for a theory of pictorial rhetoric with respect to a corpus of photographs and a piece of sculpture in the second.

\section{The demise of speculative rhetoric}

\section{Consider the following statement:}

Transuasional logic, which I term Speculative Rhetoric, is substantially what goes by the name of methodology, or better, of methodeutic. It is the doctrine of the general conditions of the reference of Symbols and other Signs to the Interpretants which they aim to determine.... (CP 2.93, 1901, my emphasis)

Although Peirce was later to reject the notion of 'doctrine' in favour of 'inquiry', this statement presents us with a progressive, positive and optimistic view of speculative rhetoric. The idea that signs 'aim' to determine their interpretants virtually aligns it with the classical tradition of the art of persuasion in spite of its evident anthropomorphism. However, in a letter to William James in which he describes a projected book on logic, Peirce is led within eight years to comment laconically on methodeutic with a simple 'My Book III treats of methods of research' (EP2: 500-2, 1909). There may be many reasons, material, financial or even scientific why Peirce should have come to prefer methodeutic to his many earlier references to formal or speculative rhetoric. However, in what follows it will be suggested that the development of his hexadic conception of sign-action provides an explanation for what happened in between these two widely differing approaches to the third component of his philosophy of representation, and, moreover, that this innovative realization of semiosis also provides a way of identifying rhetorical elements in images.

\subsection{Chronological considerations}

Before going on to set out a brief timeline of the stages in the development of Peirce's three hexadic sign-systems the reader is reminded at this point of the semiotics as Peirce had developed it in 1903. In the course of his Lowell Lectures on logic late in 1903 he established from his various definitions of the sign a triad of divisions - first two ( $\mathrm{S}-\mathrm{O}$ and $\mathrm{S}-\mathrm{I}, \mathrm{EP} 2$ 272-75) and then three (S, S - O, S - I, EP2 290-92) - based on the sign and its relations with its two correlates, namely sign and object and sign and interpretant, at this time defining methodeutic as the study of 'the principles of the production of valuable courses of research and exposition' (EP2 272). The subdivisions within each division were established by application of his three categories (Table 1). On Table 1 the icon has been replaced by its three hypoiconic structures, 


\section{Ocula $a^{15}$}

Commemorating Charles S. Peirce (1839-1914): interpretive semiotics and mass media

Tony Jappy, Peirce, rhetoric and the still image

obtained at this time by recursive application of the categories to the icon itself (EP2 273-74).

\begin{tabular}{llll}
\hline & Sign & Sign-Object & Sign-Interpretant \\
\hline Thirdness & Legisign & Symbol & Argument \\
\hline Secondness & Sinsign & Index & Dicisign \\
\hline Firstness & Qualisign & $\begin{array}{l}\text { Metaphor } \\
\text { Diagramm }\end{array}$ & Rheme \\
& & Image & \\
\hline
\end{tabular}

Table 1. Peirce's three divisions generating 10 classes of signs.

Moving on to the hexadic sign-systems, we find that Peirce developed three over the period 1904 to 1908. First and foremost in importance but not in the chronology was the hexadic process within which the sign now functioned (Figure 2) and, second, the two six-division classification systems this process generates (Figure 1 and Table 2, respectively). The following remarks form a brief timeline of the stages leading to the rejection of any form of traditional rhetorical considerations within normative science.

- In 1904 Peirce defined an initial hexad of divisions based, as in 1903, on relations between sign and correlate, two of which (S - Oi, S - Ii) were subsequently dropped (letter to LW, SS 32-35):

\section{S-Od, S-Oi, S, S-Ii, S-Id, S-If}

Figure 1. The hexad of 1904

- In 1906 he discussed a transitional hexad of 'correlate' divisions using the dicisign from 1903 as an example (the commens text: SS 197);

- In 1907 he defined semiosis as 'a coöperation of three subjects, such as a sign, its object, and its interpretant' (CP 5.484). Although never defined as such, the dynamic nature of semiosis and the order of determination was implicit in all the definitions of the sign Peirce had established earlier: the interpretant was mediately determined by the object, with the sign at the centre of the process just as it is in the expanded version on Figure 2.

Finally, in 1908, he derived a hexad of divisions based upon the correlates themselves in the order defined below, this system generating 28 classes of signs and the process in which the sign finds itself in 1908 as follows: 


\section{Ocula $a^{15}$}

Commemorating Charles S. Peirce (1839-1914): interpretive semiotics and mass media

Tony Jappy, Peirce, rhetoric and the still image

It is evident that a Possible can determine nothing but a Possible; it is equally so that a Necessitant can be determined by nothing but a Necessitant. Hence, it follows from the Definition of a Sign that since the Dynamoid Object determines the Immediate Object,

which determines the Sign itself,

which determines the Destinate Interpretant,

which determines the Effective Interpretant,

which determines the Explicit Interpretant,

the six trichotomies, instead of determining 729 classes of signs, as they would if they were independent, only yield 28 classes; (LW Dec. 23 1908; EP2 481)

This we can represent more simply by the following scheme, in which the interpretants have been standardized to immediate, dynamic and final, in that order:

\section{Od $>$ Oi $>$ S $>$ Ii $>$ Id $>$ If}

Figure 2. The hexad of 1908

- Table 2 sets out the hexad of divisions based upon the six-element determination process - semiosis - illustrated above and which, for convenience I shall refer to as 'Hexadb':

\begin{tabular}{lllllll}
\hline Universe & Od & $\mathbf{O i}$ & $\mathbf{S}$ & $\mathbf{l i}$ & Id & If \\
\hline Necessitant & collective & copulant & type & relative & usual & $\begin{array}{l}\text { to produce } \\
\text { self-control }\end{array}$ \\
\hline Existent & concretive & designative & token & categorical & percussive & $\begin{array}{l}\text { to produce } \\
\text { action }\end{array}$ \\
\hline Possible & abstractive & descriptive & mark & hypothetic & sympathetic & gratific \\
\hline
\end{tabular}

Table 2. Hexadb, the hexad of divisions yielding 28 classes of signs. ${ }^{1}$

However, before discussing this complex classification, I wish to review his 1906 transitional description of the sign and its interpretants in a draft to Lady Welby in which he introduces the notion of the 'commens' (EP2 196-97; SS 195-201). ${ }^{2}$ In this, probably the most detailed exposition of his mature the-

1 Note that the contents of the final three trichotomies are derived from the draft to LW of December 25, 1908: EP2 484-490.

2 The longer SS text comprises six pages from a 52-page draft original. 'Draft' simply because it seems unlikely that the letter was ever sent. We have a good idea of what Lady Welby received from Peirce from Appendix D in Ogden and Richards (1923). This appendix, entitled 'Some Moderns', summarizes the theories of six contemporary 


\section{Ocula $a^{15}$}

Commemorating Charles S. Peirce (1839-1914): interpretive semiotics and mass media

Tony Jappy, Peirce, rhetoric and the still image

ory of signs, and certainly to the present author's mind the most brilliant, the sign is defined in a radically different way from before. In it we find Peirce using the term 'medium' both literally as a mediating element in an expansion of the original triadic relation and metaphorically in the sense of 'vehicle', as an artist might, for whom media or vehicles such as oil or water carry pigments to make paint while in Peirce's case the sign is a medium or vehicle bearing form to produce meaning. Herewith the fundamental definition:

I use the word "Sign" in the widest sense for any medium for the communication or extension of a Form (or feature). Being medium, it is determined by something, called its Object, and determines something, called its Interpretant [...] In order that a Form may be extended or communicated, it is necessary that it should have been really embodied in a Subject independently of the communication; and it is necessary that there should be another subject in which the same form is embodied only as a consequence of the communication. (SS 196, 1906)

In this same passage, true to the principle that psychological considerations have no place in logic, Peirce downplays the influence of the utterer and interpreter on the structure of the sign: shadowy background quasi-minds 'theatres of consciousness' as he puts it in 1907 (EP2 403) - they are necessary elements of any semiosis since without them there wouldn't be a sign at all, but logically they have no influence on its structure: it is the object which 'informs' the process. Then, after having introduced the dynamic (his term is 'dynamical', but I have here, too, taken the liberty of standardizing the terminology) and immediate objects and the sign itself, he goes on to complete the description of the process as follows:

There is the Intentional Interpretant, which is a determination of the mind of the utterer; the Effectual Interpretant, which is a determination of the mind of the interpreter; and the Communicational Interpretant, or say the Cominterpretant, which is a determination of that mind into which the minds of utterer and interpreter have to be fused in order that any communication should take place. This mind may be called the commens. It consists of all that is, and must be, well understood between utterer and interpreter, at the outset, in order that the sign in question should fulfill its function. (SS 196-7, 1906)

writers on signs: Husserl, Frege, Gomperz, Bertrand Russell (a single page!), Peirce's editor James Baldwin and ten dense pages culled from Peirce's letters to Lady Welby and his 1906 Monist article 'Prolegomena to an Apology for Pragmaticism' (Ogden \& Richards, 1923: 279 - 290). There is nothing from the commens draft, so presumably Peirce either never completed it or never sent it. It comes somewhat as a surprise to find that virtually all of what we now know of Peirce's semiotics, including the important letter of December 23, 1908, in which he mentions his projected 28 and 66 classes of signs, had been published within nine years of his death, eight years before Irwin Lieb's collection of correspondence and some 35 years before Burks published the final volumes of the Collected Papers! 


\section{Ocula $a^{15}$}

Commemorating Charles S. Peirce (1839-1914): interpretive semiotics and mass media

Tony Jappy, Peirce, rhetoric and the still image

The relations between the correlates as described in 1906 can be represented in the scheme below, where, as in Figure 2 above, the symbol ' $>$ " indicates that in the order of occurrence the correlate preceding determines the one following as in the system of 1908 shown above (Figure 3):

Od, Oi, S, intentional-I, effectual-I, communicational-I

Figure 3. The hexad as described in 1906

In this system Od now consists of a set of one or more partial objects and the relations holding between them: and the process is a formalism totally devoid of subjectivity, of human intervention, of psychological bias. Nevertheless, the scheme displayed on Figure 3 calls for a number of remarks, as these will explain just why it was that Peirce was led to abandon any hopes of introducing rhetoric in his philosophy of representation along the lines of the trivium of old.

\subsection{The commens draft of March 1906}

First, we note that the scheme displayed on Figure 3 exhibits a radical principle which applies universally: the sign, even before being uttered, has been 'pre-formed' by its partial objects and the relations holding between them independently of the utterer - there can be no 'form' of any sort in a given sign that has not been inherited, so to speak, from the object. Whereas we might intuitively think that the structure of a warning such as 'There's a spider in your hair!' is determined by the 'utterer' who also, additionally adds a rhetorical element to his or her utterance - a special emphasis, for example -, what Peirce is saying here is that it is the object composed of its partials objects and the relations holding between them that structure the sign even before it is produced. It follows, therefore, that the whole process of semiosis is objective, since the sole structuring 'agency' in the process is the dynamic object with its partial objects and the relations holding between them. This means that a speculative rhetoric becomes irrelevant in logic, since any effects produced, even if they originate in an animate agent, can only enter the sign through the structure of the object if we accept the definitions above and their implications. It also means that any rhetorical intention and inflection is not 'added' to the sign in any way by the utterer, but is part of the form communicated to or extended in the sign by the object and thence to the interpretants, most notably to the intentional interpretant, which constitutes the 'sense' of the utterance - any rhetorical 'intention' the sign may convey, then, is already 'programmed' in the compound form of the object.

Second, a remarkable feature of the commens draft which makes it transitional in his developing theory of semiotics is that Peirce employs a class of signs from the 1903 period in order to illustrate his mature theory, in this case the dicisign. This class of signs has the advantage of being composed of two 


\section{Ocula $a^{15}$}

Commemorating Charles S. Peirce (1839-1914): interpretive semiotics and mass media

Tony Jappy, Peirce, rhetoric and the still image

readily identifiable parts: in the 1903 system the proposition, a dicisign, was defined as a double sign associating an index and a rheme (CP 2.251). In 1906 these two terms are dropped and Peirce simply refers to the "part appropriated to representing the object, and another to representing how [the] sign itself represents that object' (EP2 478); in other words one part representing the sign's partial objects (the indexical elements of 1903), and another representing the form of the relations holding between these partial objects. This part, unlike the first, is infinitely malleable, being 'appropriated' to represent the relations holding between these partial objects (in 1903, but no longer, this was the rhematic element of the proposition - in the commens text we see Peirce moving on), and this includes any rhetorical inflection the sign may have, as this has to be communicated to the interpretants. Note that what is left, if the sign is not dicent but 'rhematic' in the 1903 sense, is what was formerly referred to as the icon. This is the part representing the relations, including any rhetorical inflection, holding between potential partial objects, even if the sign contains no indices capable of 'proving' their existence. It is, of course, this second part which we find in the multitude of paintings to be found in museums, art galleries and our living-rooms - the icons of 1903: they are dicisigns minus the indexical element which we find in all photographs. In the verbal example above the partial objects are 'spider', 'you' and' hair', while the second part is composed of the presentative expression 'There is', the preposition 'in' and, of course, the rhetorically charged warning tone. All these diverse elements are in the form imparted to the sign and the interpretants it generates by the object: there can be no form in the sign that has not been extended by the object, and it is simply not possible for any rhetorical inflection or any form not originating in the object to be somehow 'added' at a later stage. In short, while the partial objects cannot be modified since they determined the sign in the first place, it is possible to modulate the form of the relations holding between them, including the sign's inevitable rhetorical purpose and inflection.

Third, the logical disjunction between the intentional (i.e. immediate) interpretant as a determination of the mind of the utterer and the effectual (i.e. dynamic) interpretant as a determination of the mind of the interpreter is important for another theoretical reason: it introduces a differential. Not only does the commens text confine rhetorical concerns within the objective nature of semiosis, but it also explains how signs can be misinterpreted: if the two agencies or theatres of consciousness involved in the communication have widely differing experiences of the world, then the non-deterministic basis of Peirce's semiotic theory explains those cases where the effectual interpretant is not congruent with the intentional, the utterer and interpreter being simply impersonal abstractions. This latter distinction accords with an initially surprising remark made by Peirce in a letter to Lady Welby in October 1904 to the effect that the interpretant is a determination of the 'field of the interpretant':

I define a Symbol as a sign which is determined by its dynamic object only in the sense that it will be so interpreted. It thus depends either upon a convention, a habit, or a natural disposition of its interpretant or of the field of its interpretant (that of which the interpretant is a determination). (CP 8.335) 


\section{Ocula $a^{15}$}

Commemorating Charles S. Peirce (1839-1914): interpretive semiotics and mass media

Tony Jappy, Peirce, rhetoric and the still image

In the verbal example given above the addressee might flick at his or her hair or simply thank the utterer, but might equally reply with an irate 'Mind your own business!' or 'So what!': these are all valid effectual (dynamic) interpretants, but only the first two would be congruent with the spirit of the utterance. Peirce had clearly become aware of the fact that interpreters interpret signs differentially, each according to their experience of the world; the field of the interpretant was a logical concept that accounted for this interpretive differential and reinforced the logical validity of an 'effectual' interpretant.

\subsection{Hexadb}

Finally, returning now to Table 2, we note that it displays a radically different way of classifying signs from the single division of the period from 1867 to 1901-3 and the three divisions yielding the ten classes of 1903. To begin with, the 'symbols or other signs' of the 1901 statement given above disappear from the scheme on Table 2, since the system here is based not on how a sign represents - is not based on the sign's mode of representation, in other words - but upon what it represents. In 1901, when Peirce defined speculative rhetoric as the inquiry into 'the general conditions of the reference of Symbols and other Signs to the Interpretants which they aim to determine' the classifying system, which he had considered sufficient for nearly 35 years was formed by a single division. In 1903, when he added two more divisions (Table 1 above) he referred back to it as the 'first and most fundamental [trichotomy]': 'Representamens are divided by two trichotomies. The first and most fundamental is that any Representamen is either an Icon, an Index, or a Symbol' (EP2 273). It was the 'first' because he had initially established it in 1867 , albeit with subclasses identified by slightly different appellations - the icon was termed 'likeness', and 'sign' was virtually synonymous with 'index' and thus a species of representamen - and it was 'most fundamental' since, given the fact that the object is usually absent from the situation in which signs are produced and interpreted (selfies, some personal pronouns and various demonstratives are possible exceptions), the mode of representation whether by convention, physical contact or likeness, is obviously essential to a correct understanding and interpretation of the sign and, consequently, to a correct identification of the object.

Furthermore, the fact that a sign in this new configuration is also classified not only according to its dynamic and immediate objects but also according to the nature of its three interpretants, the 'general conditions' he sought to study in 1901 had by 1906 been exhaustively identified, making the original planned research redundant. Note, too, that unlike the triadic system of 1903 with its ten classes of signs, the complex system displayed on Table 2 yields 28 classes: one class of abstractives, six of concretives and 21 (!) classes of collectives, the correct naming of which is no mean feat. Although Peirce was to refer on occasion to the sorts of universes of existence which might enable the researcher to understand the universes to which the objects which determined whether a sign was an abstractive, a concretive or a collective belonged (CP $8.178,1908$ for example), the system poses many problems of identification 


\section{Ocula $a^{15}$}

Commemorating Charles S. Peirce (1839-1914): interpretive semiotics and mass media

Tony Jappy, Peirce, rhetoric and the still image

and classification, and it is no wonder, then, that Peirce was led to abandon the idea of including rhetoric in normative science and that he never completed a description of the posited 28 and 66 classes of signs. But this doesn't mean that all hope of a Peircean rhetoric must be abandoned. It is axiomatic that all true signs must, if produced for a purpose, have a rhetorical 'component' and that Peircean logic will be able to accommodate it. So while the 1908 hexadic definition of sign-action might be seen as the high point in Peircean semiotics and the cause of his abandoning speculative rhetoric as a 'transuasional' logic, it can be shown, too, that it doesn't quite close the door on a reasoned Peircean approach to the rhetorical features of signs verbal or otherwise.

\section{Peircean contributions to a modern rhetoric}

\section{Overview}

The 1906 statements concerning the dicisign can be considered as a semiotic watershed separating the 1903 system from the full hexadic process of 1908 and Peirce's final statement on the possibility of identifying rhetorical elements in signs. In what follows, therefore, there are two sections which seek to illustrate a number of ways of looking at the rhetorical potential of photographs that Peirce's mature, hexadic system makes available: first, the 'contents' of the two parts of the dicisign as defined in the commens text; and, second, aspects of the final hexadic classification of 1908, identified above as hexadb, which enable the analyst to distinguish certain types of rhetorical inflexion in some of the classes of signs that this complex dynamic system generates. It is assumed throughout that the sort of photographs integrating a rhetorical inflection of some kind are those intended for public 'consumption', since, as Barthes once said of images in advertising, they are assuredly intentional, certainly more so than those reserved for the narrow circle of family and friends. Note, too, that although the photographic illustrations have titles, these are offered simply as vectors to the interpretation of the images: the classifications to follow concern the photograph alone, not the photograph plus title.

\subsection{The rhetorical potential of the hexad}

\subsubsection{The 1906 dicisign}

Remember from 1.2 above that in 1906 Peirce defined the dicisign not as the association of an index and a rheme as in 1903, but as being composed of two parts: one 'rigid' part appropriated to representing its partial objects and the other appropriated to representing the way the sign itself represents those objects; this latter, it was suggested, is the part which can be modulated in verbal signs with adverbials, modals, determiners, etc., and, of course, any other expressions of rhetorical purpose. Now this characteristic two-part structure is to be found, albeit less immediately obviously, in a second class of dicisign, namely the dicent sinsign illustrated by the photographs to be examined below. This is how Peirce had described the photograph in 1903, distinguishing clearly between the print itself and the section of rays which are projected from the object: 


\section{Ocula $a^{15}$}

Commemorating Charles S. Peirce (1839-1914): interpretive semiotics and mass media

Tony Jappy, Peirce, rhetoric and the still image

A better example [of an informational index] is a photograph. The mere print does not, in itself, convey any information. But the fact, that it is virtually a section of rays projected from an object otherwise known, renders it a Dicisign. [...] It will be remarked that this connection of the print, which is the quasi-predicate of the photograph, with the section of the rays, which is the quasi-subject, is the Syntax of the Dicisign; and like the Syntax of the proposition, it is a fact concerning the Dicisign considered as a First, that is, in itself, irrespective of its being a sign. (CP 2.320, 1903)

Since the prints themselves constitute the second part of each dicisign which represents itself to be representing the nature of its object while the objects themselves can be considered to be represented as the sections of rays, we can take it that both parts coexist in the same sign in the form of a blend. The problem facing the analyst is simple: since all dicisigns, in order to belong to the class, must share the same properties, in one sense they are all identical. By this reasoning, rather like Nelson Goodman's remark that a Constable painting of Marlborough Castle doesn't resemble the said building, but, rather, any other painting (1976: 5), all photographs, qua dicisigns, are identical. In order to differentiate them we can adopt at least two strategies. In the first case, as most people do when they examine a photograph, we can 'enter' the print and identify its various elements. In the second we can examine the way photographic signs relate to the three interpretants that they necessarily determine with respect to certain of the 28 classes set out on Table 2 above.

With this in mind we examine a number of examples, showing simply, as every photographer knows, how the print is the locus for rhetorical intervention or manipulation. As an example of the first strategy, consider Figures 4 and 5 . Clearly, the objects which determined each photograph - human beings, furniture, a glass of white wine, etc. - are present in the photographs and are, in an important but logically irrelevant way, the result of choices on the part of the photographer. However, concentrating solely on the human element in each case, we see how the part of these particular dicent sinsigns appropriated to 'representing how [the] sign itself represents that object' can be analysed in terms of the various indexical nonverbal communication signs (NVC signs) ${ }^{3}$ each presents: photographs are by nature mute and can only appeal to a mind and affect it by visually salient features such as these NVC signs. To simplify, we examine a limited number of such NVC signs visible in the images, namely proximity, orientation and posture, although other NVCs such as facial expression, gesture and appearance all contribute meaning to pictorial and verbal signs as examples of significant embodied indices.

3 There are many studies of nonverbal communication. See Argyle (1972) or Guiraud (1980), for example. 


\section{Ocula $a^{15}$}

Commemorating Charles S. Peirce (1839-1914): interpretive semiotics and mass media

Tony Jappy, Peirce, rhetoric and the still image

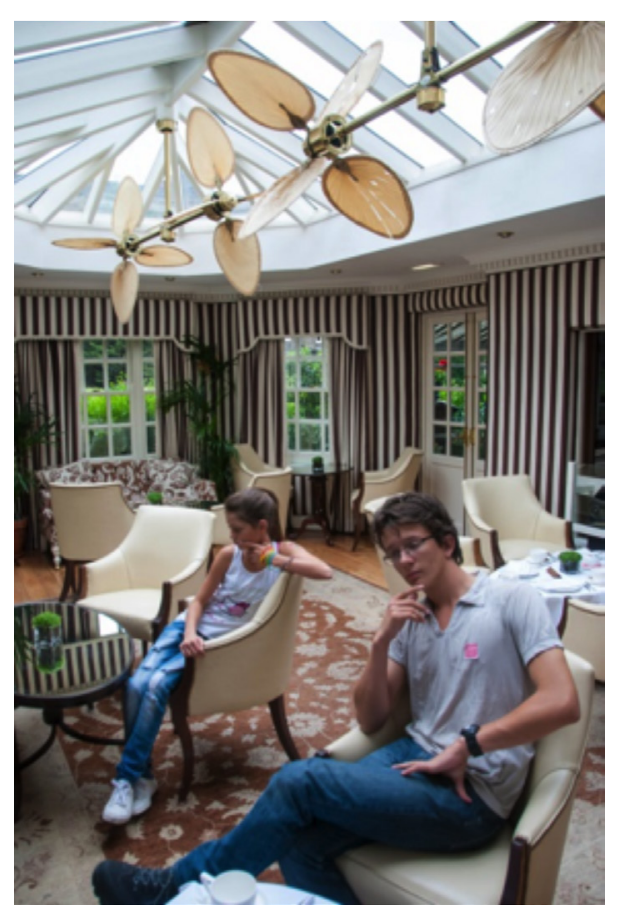

Figure 4. Ennui (@Pascal Jappy).

A NVC sign such as proximity or interpersonal spacing tends to be culturally variable, and is often associated with orientation, which is the angle at which people sit or stand in relation to others. Two distinct combinations of interpersonal spacing and orientation are evidenced by Figures 4 and 5: distance and non-congruent orientation suggesting boredom or daydreaming in Figure 4 and relative proximity and mutual interest in Figure 5. Moreover, a formal type of orientation is head-on, as it promotes eye contact and ensures efficient communication as in confrontation and bargaining, etc., (Figure 5) as opposed to side-by-side orientation, which is generally an indication of cooperative relations and the orientation of friends together.

Another type of NVC sign contributing to the way these signs represent their objects is posture. This is an interpersonal attitude, and can be an indication of one's emotional state along a tense - relaxed dimension. The state of mind or degree of attention of an audience, of students, say, can easily be recognized from the posture of its members: slouching indicates disappointment, boredom or lack of interest (Figure 4), whereas the (relatively) upright posture (Figure 5) of the seated figures suggests attention and possibly adhesion to the speaker's remarks. 


\section{Ocula $a^{15}$}

Commemorating Charles S. Peirce (1839-1914): interpretive semiotics and mass media

Tony Jappy, Peirce, rhetoric and the still image

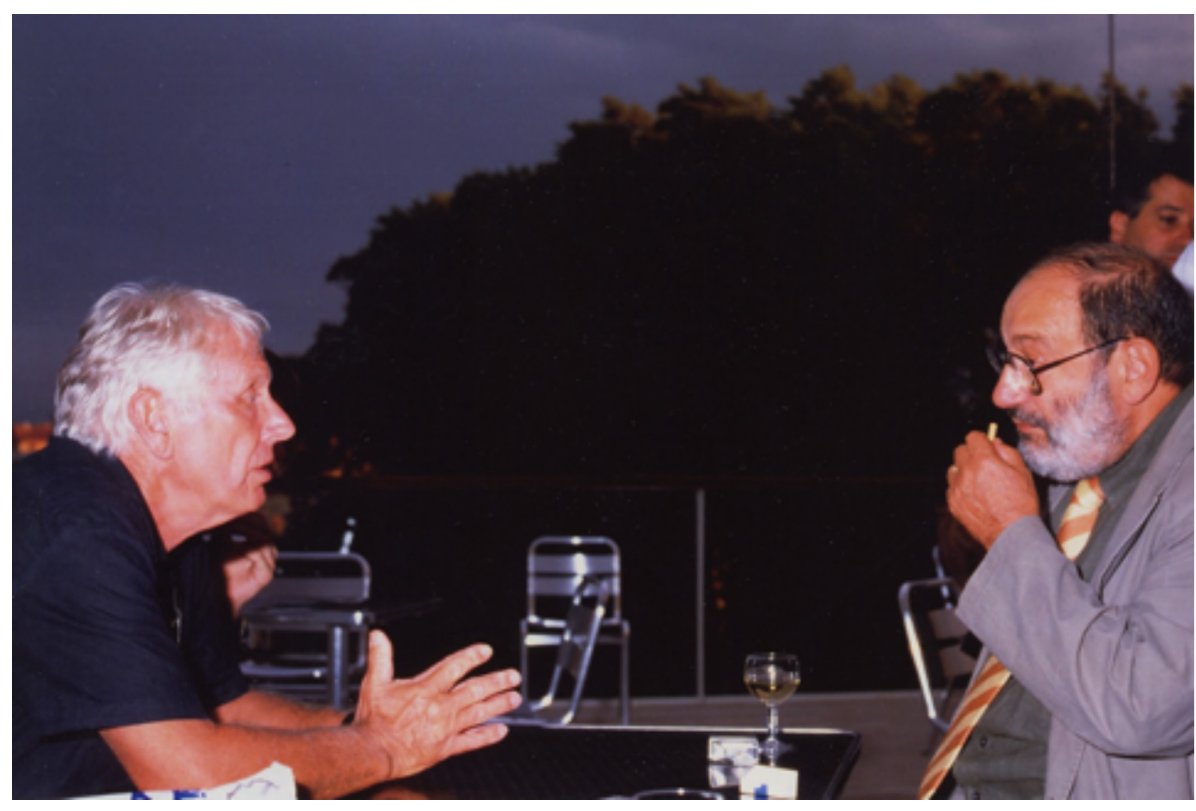

Figure 5. Negotiations, Perpignan 2002

Now all these NVC features contribute to the rhetoric of the photographs, albeit in subtle ways. They constitute readily identifiable features of the part of the sign appropriated to representing the relations holding between the sign's partial objects, that part of the photograph that Peirce defined as its 'quasi-predicate' in 1903. In this guise, no less than, say, such types of mass media nonverbal conventions as the various cropping and filtering strategies the photographer has at his disposal, these features necessarily contribute to the complex form conveyed by the sign to its sequence of three interpretants, i.e. to the three increasingly complex logical effects that the sign has on the agency interpreting it; and to the extent that the photograph is the vector of a deliberate attempt to influence any observer it may have, they contribute to its meaning by offering a specific rhetorical inflection.

\section{$2.2 \operatorname{Hexadb}$}

\subsubsection{Photography}

We now turn to the possibilities for the rhetorical investigation of photographs made available by Peirce's 1908 typology set out on Table 2 above. Unlike the highly problematic 66 classes that Peirce mentioned in his letter to Lady Welby of December 23, 1908, the 28-class structure functions perfectly, allows the analyst to classify signs and contributes to an investigation of their rhetorical inflection. In what follows, some of the illustrations have been chosen because they do not necessarily involve NVC signs of the sort examined above. Moreover, owing to copyright restrictions, it has not been possible to give well known instances from the rich tradition of photographic art. For this 


\section{Ocula $a^{15}$}

Commemorating Charles S. Peirce (1839-1914): interpretive semiotics and mass media

Tony Jappy, Peirce, rhetoric and the still image

reason some of the classes of signs discussed below have, in the endnotes, a URL leading to material from the Mark Harden Artchive Masters of Photography gallery, while contemporary examples have generously been provided by the travel photography specialist, Pascal Jappy, and readers interested in all things photographic should visit his photography blog. ${ }^{4}$

Returning now to the classifying system on Table 2, it should be remembered that it is based not on relations between the sign and its various correlates in the process of sign-action as in the case of the icon-index-symbol division, for example, but on what Peirce refers to as their 'ultimate reference' (EP2 480, 1908), i.e. on the nature of their dynamic object, and on the other correlates taken individually in the order in which they 'occur' logically in semiosis. As a class of indices photographs typically represent existent objects, objects located in the universe that Peirce identifies as 'Occurrences' or 'Existents' and the facts pertaining to them (EP2 479-80, 1908): it is not possible, theoretically, to take a photograph of something that does not exist. At first glance, therefore, most if not all photographs can be classified as concretives. However, the strictly rhetorical purpose of the photograph, as with any sign, concerns the appeal of the sign to its various interpretants, and in what follows I shall outline classes of signs according to the nature of their immediate, dynamic and final interpretants in the order indicated on Table 2, noting first that all photographs, as they do not normally function as elements of a system, are tokens, by which term is meant in the 1908 system not only what were originally referred to as instances or replicas of legisigns but also uniquely occurring sinsigns - 'something that once uttered is gone forever' (EP2 403, 1907). With this in mind we now classify the rhetorical appeal of a number of photographs with respect to their three interpretants, applying, in the classification, the principle stated above by Peirce that "a Possible can determine nothing but a Possible; it is equally so that a Necessitant can be determined by nothing but a Necessitant". This is what the late Gérard Deledalle referred to as the' hierarchy of the categories' and Savan (1988: 5), the 'qualification rule'.

According to the Ii division, signs can be relative, categorical or hypothetic. A relative sign would be of the nature of an If... Then conditional sentence, or some form of inference. A typical example of a hypothetic sign would be a captionless nonfigurative painting, a sign identified as an icon in the 1903 typology. Photographs, on the other hand, represent readily identifiable real objects and are therefore categorical signs.

It is within the Di division that differences between types of photograph really appear and enable the analyst to come to decisions concerning their rhetorical inflection. At this point there is a choice between percussive and 'congruentive' or sympathetic signs (note that Peirce was not entirely happy with all the labels he gave to these subclasses, but it is nevertheless remarkable that he should have managed to label them at all). Typical examples of concussive photographs - photographs which produce not simply a sentiment or feeling but a brute reaction - are those taken in times of conflict - social, international, personal or otherwise - in photojournalism and documentary

4 http://www.dearsusan.net/ 


\section{Ocula $\mathbf{a}^{15}$}

Commemorating Charles S. Peirce (1839-1914): interpretive semiotics and mass media

Tony Jappy, Peirce, rhetoric and the still image

photography, for example. They are percussive because they produce a disturbance of the psychic equilibrium of the interpreter: 'percussive' simply means that they produce a dynamic effect in the interpreter. This would also be the case with pornography, presumably, and no doubt Italian readers of this journal will have found the image on Figure 5 percussive... On the other hand congruentive or sympathetic photography will often be realized as family photos, wedding photography and portraits, etc., and will typically appeal to instinct and feelings as in e.g. Figure 6.

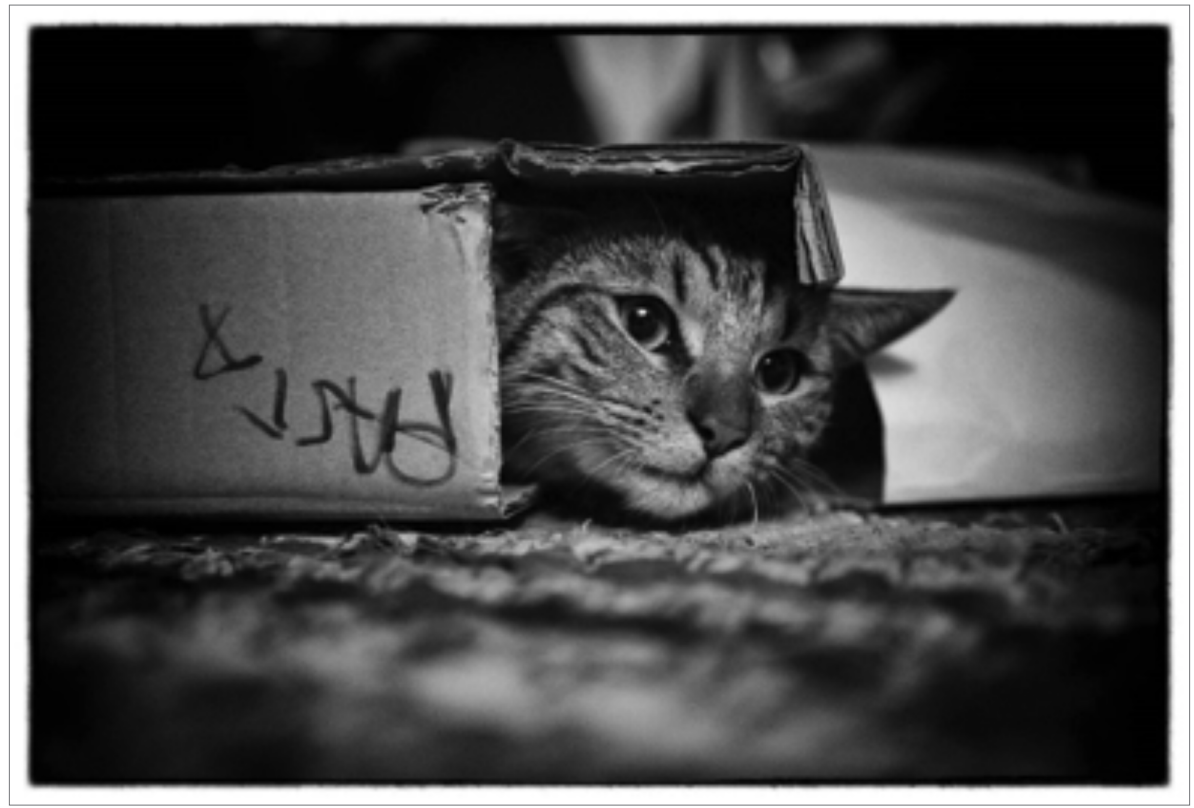

Figure 6. Attila (C) Pascal Jappy).

Finally, the Fi division allows further rhetorical distinctions (remember that any appeal to an interpretant is rhetorical by definition). At this final point in the sequence the Fi division selects between action-producing and gratific signs. We now have the beginnings of a set of classes of signs for photographs. ${ }^{5}$

5 Given the number of different labels and the fact that most are adjectival, naming the class in a coherent and sensible manner is not always simple. In what follows adjectival terms will precede the term 'token', even if the term 'token' occurs earlier in the process. Items in parentheses are included for clarity even though it is not strictly necessary to specify them. 


\section{Ocula $a^{15}$}

Commemorating Charles S. Peirce (1839-1914): interpretive semiotics and mass media

Tony Jappy, Peirce, rhetoric and the still image

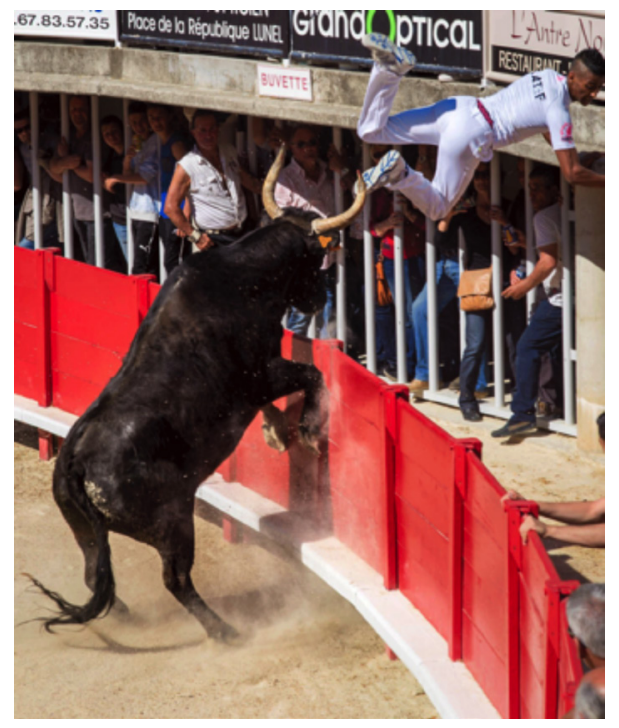

Figure 7. Raseteur volant (@Pascal Jappy).

For example action-producing (categorical) (percussive) concretive signs are typically the photographs of photojournalism and reportage photography, the photographs of advertising or consciousness-raising campaigns the purpose of which being to dissuade or persuade: photographic illustrations of recent anti-HIV or anti-smoking campaigns are good examples. Concretive (categorical) (percussive) gratific tokens are typical of the work of photographic artists such as Diane Arbus ${ }^{6}$ and Garry Winogrand: ${ }^{7}$ they are deliberately shocking but not intended to produce any significant action, for their ultimate appeal is more to feeling and instinct. Another illustrious exponent of this sort of highly percussive street photography is Weegee, while the image on Figure 7 offers a dramatic but less polemical example. Finally, categorical sympathetic concretives are also logically gratific: they appeal to our sense of beauty or to the emotions without any intention to shock or surprise the observer. Figure 6 is a homely example of this category, and the atmospheric aesthetics of Figure 8 reflects the sensitive, sympathetic i.e. non-percussive style which characterizes much of Edward Weston's art photography. ${ }^{8}$

6 Cf. e.g. http://en.wikipedia.org/wiki/Diane_Arbus

7 Cf. e.g. http://masters-of-photography.com/W/winogrand/winogrand_rhinos. html

8 Cf. e.g. http://masters-of-photography.com/W/weston/weston_white_dunes.html 


\section{Ocula $a^{15}$}

Commemorating Charles S. Peirce (1839-1914): interpretive semiotics and mass media

Tony Jappy, Peirce, rhetoric and the still image

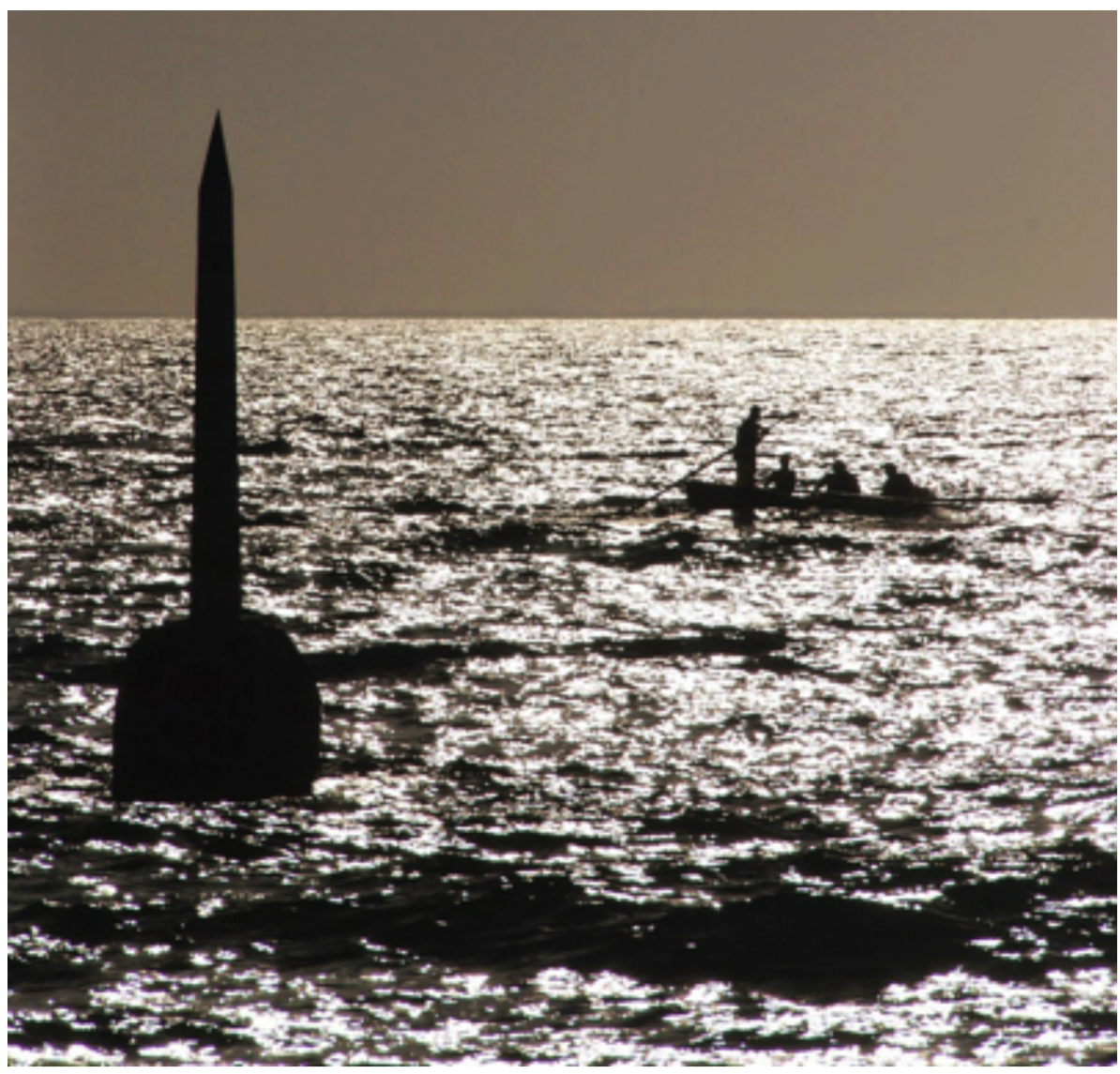

Figure 8. Bosporus (CPascal Jappy).

The discussion and examples above offer a range of classes identified according to the appeal they have for their series of interpretants, and to this extent contribute to a very different conception of a rhetoric of not only images such as paintings and photographs, but also of the complex verbal signs of our everyday intercourse with others. However, identifying the sign-type with respect to the three interpretants is not the only innovative contribution hexadb makes to rhetoric studies. Until now it was suggested that all photographs, as a consequence of the existential relation holding between them and the members of the universe of existents that they represent, were by definition concretive signs. This is not entirely true, and by examining the photograph's relation to its object it is possible to distinguish between what traditionally would be considered as literal and figurative inflections.

Consider, first, the example of Cindy Sherman's untitled film still series of 1977, in which she photographs herself in the guise of a film actress in over seventy different poses. ${ }^{9}$ Although each film still is concretive to the extent that it represents an existent object - a young woman in a definite context the fact that we have a photographer simulating an actress who by profession

9 Cf. e.g. http://masters-of-photography.com/S/sherman/sherman_10_full.html 


\section{Ocula $a^{15}$}

Commemorating Charles S. Peirce (1839-1914): interpretive semiotics and mass media

Tony Jappy, Peirce, rhetoric and the still image

simulates events from real life herself, converts the universe of existents to that of necessitants and these images from concretives to collectives: there are two distinct but related objects in each case, the original of which is as though 'hidden' behind the visible second in this collective categorical sympathetic token.

A further case of how rhetorical concerns can promote a photograph from concretive to collective by a form of figurative transformation is provided by the work of Jerry Uelsmann. His Symbolic Mutation of $1961^{10}$ is a fine example of how in a single image the artist has blended elements from two worlds, the male and the female, blending two distinct negatives by means of his postproduction technique. The seemingly brutal world of the male and that of the female victim are signified by synecdoche: the hairy-knuckled fist of the male encloses the vulnerable face of the female, and the two worlds are combined in a copulant percussive token. This suggests that whenever a sign represents elements drawn from two distinct and non-congruent universes it is necessarily both collective and figurative. This is the case, too, with such collective copulant verbal signs as That surgeon is a butcher or Life is a walking shadow, etc., both of which establish a copular relation between elements drawn from distinct universes: surgery practiced on humans and the butchering of cattle for food in the first case, and life and the shadows reflected in Plato's cavern in the second. Both are tokens of copulant action-producing types (remember that if they are copulant, they cannot be other than collective).

\subsubsection{Sculpture}

The foregoing remarks have shown how divisions from both extremities of the classification system obtained from the 1908 conception of sign action can contribute to and, hopefully, renovate the discussion of the rhetoric of still images. But before closing the discussion, I should like to examine a very different case of visual rhetoric, namely a piece of sculpture (Figure 9). Entitled Melencolia due, it is a contemporary exemplar of a thematic tradition reaching back no doubt to Antiquity via Rodin, Dürer and Raphael's Michelangelo in the School of Athens. Unlike the photographs above, this has to be taken with its title, as without it the sculpture is simply an assembly of scrap metal. In the 1903 system the complete sign would be classified as a dicent indexical legisign. The title, two words from the Italian language, forms a proper noun, an indexical legisign, while the syntax associating title and sculpture makes the whole dicent.

10 Cf. e.g. http://masters-of-photography.com/U/uelsmann/uelsmann_symbolic_ mutation_full.html 


\section{Ocula $a^{15}$}

Commemorating Charles S. Peirce (1839-1914): interpretive semiotics and mass media

Tony Jappy, Peirce, rhetoric and the still image

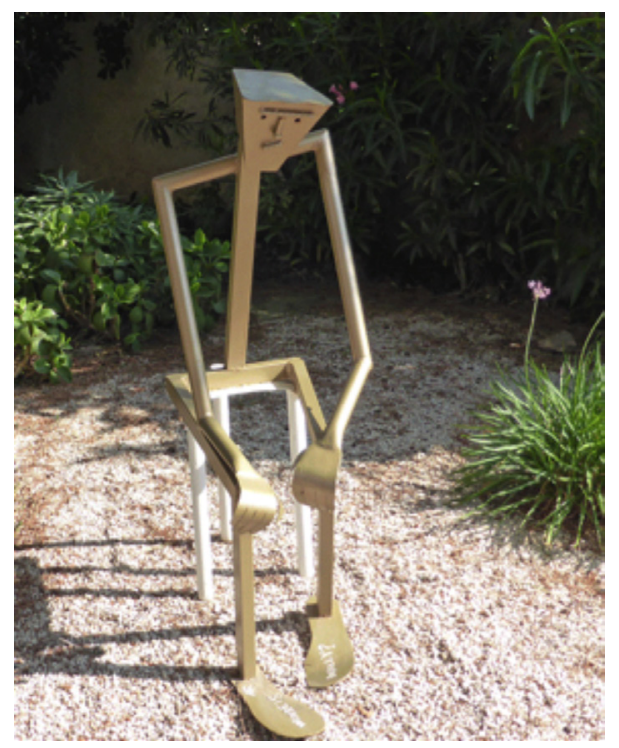

Figure 9. Melencolia due, courtesy of the artist, Adrian Tee.

In itself the sculpture is a degenerate index:

A genuine Index and its Object must be existent individuals (whether things or facts), and its immediate Interpretant must be of the same character. But since every individual must have characters, it follows that a genuine Index may contain a Firstness, and so an Icon as a constituent part of it. Any individual is a degenerate Index of its own characters. (CP 2.283, 1903)

That is, it simply displays a set of properties or characters which are so arranged as to enable us to identify a man seated with a frown on his face. Within the scope of the distinctions afforded by hexadb, the work is necessarily collective since the association of title and sculpture realizes the ' - is -' syntax characteristic of one class of collectives (CP 8.350) even though the dynamic object of the sculpture itself is a man and therefore an existent (remember that it is the reference, not the sign, which constitutes the existent). It is thus necessarily copulant. Unlike the verbal examples examined above, this cannot be a type and must therefore be classified as a token. As a recognisable representation of a human being its appeal to its immediate interpretant is existential: from this first rhetorical criterion the sculpture is categorical; its appeal to its dynamic interpretant is probably percussive, as such a personification of the concept of melancholy is unusual, which precludes it from being a sympathetic or 'congruentive' sign. In spite of this its appeal to the final interpretant is aesthetic and the sign is necessarily gratific, even if the deliberately angular construction of the whole may not please everyone. The analysis, which is explicitly rhetorical in nature, unlike the system of 1903 with its informational scope, yields a collective percussive gratific token. While this label, like those applied to the photographs, will no doubt seem barbaric to the more sensitive 


\section{Ocula $a^{15}$}

Commemorating Charles S. Peirce (1839-1914): interpretive semiotics and mass media

Tony Jappy, Peirce, rhetoric and the still image

reader, the choices leading to the final classification are genuinely rhetorical in scope, and constitute a novel approach to signs such as the photographs and a piece of sculpture.

\section{Conclusion}

The preceding remarks were intended as an explanation of Peirce's rejection of the principle of a transuasional logic that would have continued, within the grand logic of 1903, the rhetoric of the tradition, and, at the same time as an introduction to the analytical possibilities offered by the very hexadic system which rendered speculative rhetoric redundant. It was not intended as an introduction to the meaning of photographs along the lines of Terry Barrett's excellent monograph (Barrett 1990), although hexadb does provide us with a heuristic with which to investigate important aspects of the rhetoric of images. It was also a pretext for the exploration of the powerful classificatory system that Peirce left behind a hundred years ago, and at the same time an attempt to go beyond the sempiternal recourse to the icon-index distinction in the discussion of pictorial signs. Finally, it should be borne in mind that hexadb was not conceived specifically for rhetorical analysis: the two 'prongs' of Peirce's innovative assault on traditional logic were definition and classification and the 28 classes generated by hexadb were a late instance of his attempt to classify the signs to be investigated by logic. Similarly, the analyses obtained from this typology are not intended to constitute an alternative to classical rhetoric but, rather, to offer further instruments for the analysis of rhetorical phenomena.

\section{References}

Argyle, M.

1972 "Non-Verbal Communication", in R. A. Hinde, (ed. Non-Verbal Communication, London: Cambridge University Press, pp. 243-69.

Barrett, T.

1990 Criticizing Photographs: An Introduction to Understanding Images, Mountain View, CA: Mayfield.

Goodman, N.

1976 Languages of Art: An Approach to the Theory of Symbols, Indianapolis and Cambridge: Hackett Publishing Co.

Guiraud, P.

1980 Le Langage du corps, Paris: Presses Universitaires de France.

Jappy, T.

2013 Introduction to Peircean Visual Semiotics, London: Bloomsbury. 


\section{Ocula ${ }^{15}$}

Commemorating Charles S. Peirce (1839-1914): interpretive semiotics and mass media

Tony Jappy, Peirce, rhetoric and the still image

Ogden, C. K. \& I. A. Richards,

(1923 The Meaning of Meaning: A Study of the Influence of Language upon Thought and of the Science of Symbolism, New York: Harcourt, Brace \& World.

Peirce, C. S.

1931-58 Collected Papers of Charles S. Peirce, Hartshorne, C., Weiss P. \& Burks, A., (Eds.). Cambridge, MA: Harvard University Press. (CP)

1998). The Essential Peirce, Volume 2. Peirce Edition Project, (Eds. Bloomington: Indiana University Press. (EP2)

Peirce, C. S. and V. Welby-Gregory

(1977). Semiotic and Significs: The Correspondence between C. S. Peirce and Victoria Lady Welby, Hardwick, C. S. (ed.). Bloomington: Indiana University Press. (SS)

Savan, D.

1988 Introduction to C.S. Peirce's Full System of Semeiotic, Toronto: Toronto Semiotic Circle.

Tony Jappy is professeur honoraire at the University of Perpignan Via Domitia, France. He has participated in numerous semiotics and visual semiotics colloquia and congresses, the most recent being the Peirce Centennial Conference at Lowell, Massachusetts, has published numerous articles on problems relating to linguistics and semiotics and visual semiotics, and has authored and co-authored several books, the most recent being an introduction to Peircean visual semiotics in 2013. His current research is devoted primarily to C. S. Peirce's post-1904 system of semiotics. 